\title{
Platinum-Based Alloys: Investigation of the Effect of Impurities Content on Creep Rate, Rupture Time and Relative Elongation at High Temperatures
}

\author{
Biserka Trumića, Lidija Gomidželovića ${ }^{*}$, Saša Marjanovičb , Aleksandra Ivanovića ${ }^{a}$,Vesna Krsticića \\ ${ }^{a}$ Mining and Metallurgy Institute Bor, Zeleni bulevar, 35, 19210, Bor, Serbia \\ ${ }^{b}$ University of Belgrade, Technical Faculty, VJ 12,19210, Bor, Serbia
}

Received: March 22, 2016; Revised: October 7, 2016; Accepted: November 21, 2016

\begin{abstract}
This paper presents the results of research of the effect of impurities content on high-temperature resistance of selected platinum alloys. Alloys of following systems were investigated: Pt-Rh, Pt-Rh-Pd, Pt-Rh-Pd-Ru and Pt-Rh-Pd-Ir-Au. Universal device for tensile testing of materials at high temperatures was used for examination. Investigations were carried out in a temperature range of $1300-1400{ }^{\circ} \mathrm{C}$, with a stress of $5 \mathrm{MPa}$. It was observed that an increase in content of impurities in tested alloys at high temperatures, and at stated conditions of stress, caused a noticeable increase in creep rate while reducing rupture time and relative elongation. Experimental results confirmed that probability of brittle fracture decreases with decreasing impurity content in the alloys. Binary and multicomponent alloys of Pt-Rh, Pt-Pd-Rh, Pt-Rh-Pd-Ru and Pt-Rh-Pd-Ir-Au systems are primarily used in conditions of high temperature, and accordingly, presented results contribute to a better understanding of their behavior in such working conditions.
\end{abstract}

Keywords: Platinum-based alloys, impurities, creep rate, rupture time, relative elongation

\section{Introduction}

Platinum $(\mathrm{Pt})$ is dense, stable, malleable, ductile, biologically compatible, gray-white, precious, rare transition metal with good electrical conductivity, belonging to platinum group metals (PMGs) which also include iridium (Ir), Osmium (Os), Palladium (Pd), Rhodium (Rh) and Ruthenium (Ru). All this metals are extremely rare, very durable and due to their high price, often recycled.

Annual production of platinum is around few hundred tones making it very scarce and valuable. The largest amount of platinum is used in jewelry industry (about $40 \%$ of annual production), but this metal is also crucial for many catalytic processes, and holds important role for electronic industry and medicine.

Platinum is often alloyed with other PGMs in order to improve durability at high temperatures. Interest of researches in platinum based alloys is constantly growing ${ }^{1}$. These types of alloys are used in: glass industry ${ }^{2,3}$, fertilizer plants ${ }^{4-6}$, temperature measurement ${ }^{7}$, environment protection ${ }^{8}$, jewelry production ${ }^{9,10}$, shape memory applications $\mathrm{s}^{11,12}$ and medicine ${ }^{13}$.

Different Pt-based alloys are primarily used in various high temperature applications, so knowledge of their properties under such conditions is crucial for successful utilization.

Alloys of platinum with rhodium content up to $20 \%$ are most commonly used in high temperature aplications, but compositions with rhodium up to $30 \%$ are also utilized. Platinum-iridium allys are not used often like platinum-rhodium alloys, but iridium in small amout (up to $1 \%$ ) can improve

* e-mail: lgomidzelovic@yahoo.com platinum microstructure stability at high temperatures, without significantly affecting mechnical strenght. Higher contents of iridium in platinum-based alloys can lead to poor oxidation resistance and ebrittlement. Using gold as alloying element leads to significant increase of molten glass contact angle on surface of platinum-based alloy.

Some of platinum-based alloys published research results include:

- thermodynamics and phase equilibrium of binary Pt-Rh system ${ }^{14}$.

- thermal and mechanical properties of Pt-Rh alloys ${ }^{15}$.

- microstructural analysis of selected platinum alloys used in industry and jewelry making (including PtRh10, PtRh30, Pt-5Ru, Pt-5Ir, Pt-5Au and Pt25Ir-15Rh $)^{16}$.

- $\quad$ Pt-Rh, Pt-Pd, Pd-Rh and Pt-Pd-Rh phase diagrams examined using Monte Carlo simulation method in combination with MEAM method and optimized parameters ${ }^{17}$.

- creep rate and rupture time of Pt-Rh alloys at high temperatures ${ }^{18}$.

The aim of this paper is to examine the impact of harmful impurities on high temperature resistance of Pt-Rh, Pt-Rh-Pd, Pt-Rh-Pd and Pt-Ru-Rh-Pd-Ir-Au alloys.

The presence of chemical elements - impurities in the platinum metals and alloys is associated with the composition of the starting ore deposits as well as the technological processes for their obtaining, processing and exploitation in industrial conditions ${ }^{19-21}$.

The presence of impurities in platinum metals and alloys has a large impact on their physical and mechanical 
properties. For this reason, the purity of platinum metals and alloys is one of their main characteristics. It is determined by calculation, from the difference between $100 \%$ weight of the metal and the sum of percentages of 10-15 control impurities. In addition, in the total number of control impurities, as a rule, there are the platinum group metals and gold. Impurities such as $\mathrm{Rh}, \mathrm{Ru}, \mathrm{Pd}, \mathrm{Ir}$ and $\mathrm{Au}$ lead to the improvement of mechanical properties of platinum, ie to increase of its high temperature resistance. In addition to these "good" impurities there are harmful impurities, 50-70 so-called non control impurities, in a total concentration of $10^{-2}-10^{-3} \%$ (wt.\%). This work aimed to show how various contents of impurities affect the high-temperature characteristics of platinum materials, at a constant temperature and stress. The results are only part of the multi year researches of platinum materials at high temperatures, which find application in the glass industry for molding optical fiber.

\section{Experimental}

Platinum, rhodium and palladium for alloys production have been obtained as a side product in the production of electrolytic copper RTB, Serbia. By additional refinement the necessary purity for samples production has been achieved (99.98\% for Pt, 99.95\% for $\mathrm{Rh}$ and $\mathrm{Pd} 99.98 \%$ ). The composition of the samples is given in Table 1.

Impurities in the samples were characteristic for raw material of Bor deposits - Si, Sb, Fe, Al, Mg, Ag, Bi, Sb, $\mathrm{As}, \mathrm{Cu}$.

Melting of the samples was carried out in a mediumfrequency induction furnace. Annealing of the samples was carried out in an electro resistant furnace type LP08, for 20 minutes at $900^{\circ} \mathrm{C}$.

For testing the mechanical properties of samples at high temperatures a universal device for tensile testing of materials at high temperatures, by manufacturer Karl Frank, type 81221 , was used.

Chemical analysis of materials for samples was performed on atomic absorption spectrophotometer. Examination of the microstructure was performed on samples measuring $1,7 \times 1,7 \mathrm{~mm}$, which were prepared according to standard procedure - grinding, polishing (polishing machine ROWA E KG) with $0,05 \mu \mathrm{m} \mathrm{Al}_{2} \mathrm{O}_{3}$ powder, and etched a few seconds with aqua regia $\left(100 \mathrm{~cm}^{3}\right.$ $\mathrm{HCl}$ and $30 \mathrm{~cm}^{3} \mathrm{HNO}_{3}$ ). Changes in the structure were observed using optical and scanning electron microscope. Optical microscopy was performed on metallographic microscope EPYTIP 2, at different magnifications. Scanning-electron microscopy (SEM) was performed on electronic microscope JEOL JSM-6610LV with resolution of $10 \mathrm{~nm}$ on $20 \mathrm{keV}$, accelerating voltage of $3-30 \mathrm{kV}$ and magnification up to $300000 \mathrm{x}$.

\section{Results and Discussion}

In order to supplement the existing database of platinum and platinum metals, originating from the Bor deposites in Serbia, as well as having the information about the practical implementation of the above mentioned at high temperatures, investigations were carried out on the influence of impurities on the mechanical properties of the alloys of Pt-Rh, Pt-Rh-Pd, Pt-Rh-Pd-Ru and Pt-Rh-Pd-Ir-Au systems, with platinum as base metal, and alloying elements $\mathrm{Rh}$ (15-20 wt\%), Pd (10$25 \mathrm{wt} \%), \mathrm{Ru}(1.5 \% \mathrm{wt}),. \mathrm{Ir}(0.1 \% \mathrm{wt}$.) and $\mathrm{Au}(0.1 \% \mathrm{wt}$.$) .$

Since platinum metals alloys can contain a range of impurities, it is very difficult to determine the individual effect of each one to high-temperature resistance of alloys. For the practical application of platinum alloys, it is important to have knowledge of individual as well as the group effect of impurities on the creep resistance (creep life) and the destruction of the alloys.

The values of the minimum creep rate (in the rest of paper creep rate) and rupture time of the alloy $\mathrm{PtRh} 7$ at 1300 and $1400{ }^{\circ} \mathrm{C}$, at a stress of $5 \mathrm{MPa}$, are given in Table 2 .

For PtRh7 alloy, in the temperature interval of 1300-1400 ${ }^{\circ} \mathrm{C}$, at a stress of $5 \mathrm{MPa}$, based on the results shown in Table 2 , at the total content of the impurities $0.05 \%$ (sample No. 1 ) creep resistance is twice as big, and the rupture time twice shorter, as compared with the sample number 7 , wherein the total impurity content is $0.013 \%$.

Based on the results in Table 2, it can be seen that in the total content of impurities, the largest share belongs to: $\mathrm{Si}, \mathrm{Fe}, \mathrm{Al}$ and $\mathrm{Mg}$.

The effect of impurities on creep rate, rupture time and relative elongation, at the temperature of $1400{ }^{\circ} \mathrm{C}$, at a stress of $5 \mathrm{MPa}$, for the alloys PtRh10, PtRh5Pd15 and PtRh10Pd25Ru1.5 is shown in Tables 3, 4 and 5.

Based on the results presented in Table 3, for the alloy PtRh10, at a temperature of $1400{ }^{\circ} \mathrm{C}$ and a stress of $5 \mathrm{MPa}$, the same rule applies as to the alloy PtRh7 under the same

Table 1: The content of alloying elements in the investigated alloys (mass\%)

\begin{tabular}{|c|c|c|c|c|c|}
\hline Alloy & $\mathrm{Rh} / \%$ (wt.) & $\mathrm{Pd} / \%$ (wt.) & $\mathrm{Ru} / \%$ (wt.) & Ir / \% (wt.) & $\mathrm{Au} / \%$ (wt.) \\
\hline PtRh7 & 7 & - & - & - & - \\
\hline PtRh10 & 10 & - & - & - & - \\
\hline PtRh5Pd15 & 5 & 15 & - & - & - \\
\hline PtRh10Pd25Ru1.5 & 10 & 25 & 1.5 & - & - \\
\hline PtRh20Pd10Ir0.1Au0.1 & 20 & 10 & - & 0.1 & 0.1 \\
\hline
\end{tabular}


Table 2: Characteristics of high-temperature resistance of alloy PtRh7 depending on impurity content at 1300 and $1400{ }^{\circ} \mathrm{C}$ and stress of $5 \mathrm{MPa}$

\begin{tabular}{|c|c|c|c|c|c|c|c|c|c|c|c|}
\hline \multirow{2}{*}{ Sample } & \multicolumn{7}{|c|}{ Content of impurities / \% (wt.) } & \multicolumn{2}{|c|}{$\dot{\varepsilon} / \% \mathrm{~h}^{-1}$} & \multicolumn{2}{|c|}{$t / h$} \\
\hline & $\mathrm{Si}$ & $\mathrm{Sb}$ & $\mathrm{Fe}$ & $\mathrm{Cu}$ & $\mathrm{Pb}$ & Al & $\mathrm{Mg}$ & $1300^{\circ} \mathrm{C}$ & $1400^{\circ} \mathrm{C}$ & $1300^{\circ} \mathrm{C}$ & $1400{ }^{\circ} \mathrm{C}$ \\
\hline 1 & 0.013 & 0.007 & $<0.01$ & 0.0073 & 0.005 & 0.002 & 0.006 & 0.42 & 1.14 & 55 & 28 \\
\hline 2 & 0.007 & 0.004 & $<0.01$ & - & 0.003 & $<0.002$ & 0.003 & 0.18 & 0.96 & 63 & 38 \\
\hline 3 & 0.008 & 0.006 & $<0.01$ & 0.005 & 0.004 & $<0.002$ & 0.013 & 0.132 & 0.582 & 56 & 40 \\
\hline 4 & 0.01 & 0.003 & $<0.01$ & - & 0.001 & $<0.002$ & - & 0.15 & 0.552 & 104 & 34 \\
\hline 5 & - & - & $<0.01$ & - & $<0.001$ & $<0.002$ & - & 0.198 & 0.906 & 86 & 46 \\
\hline 6 & - & - & $<0.01$ & - & $<0.001$ & $<0.002$ & & 0.186 & 1.14 & 85 & 47 \\
\hline 7 & - & - & $<0.01$ & - & $<0.001$ & $<0.002$ & & 0.20 & 0.582 & 103 & 54 \\
\hline
\end{tabular}

* all elements with symbol $<$ are below the detection limit of AAS (method used to determine the content)

Table 3: The values of the creep rate, rupture time and relative elongation depending on the content of impurities at a temperature of 1400 ${ }^{\circ} \mathrm{C}$, at a stress of $5 \mathrm{MPa}$, for the alloy PtRh10

\begin{tabular}{|c|c|c|c|c|c|c|c|c|c|}
\hline \multirow[b]{2}{*}{ Sample } & \multicolumn{6}{|c|}{ Content of impurities / \% (wt.) } & \multirow[b]{2}{*}{$\dot{\varepsilon} / \% \mathrm{~h}^{-1}$} & \multirow[b]{2}{*}{$t / h$} & \multirow[b]{2}{*}{$\mathrm{A} / \%$} \\
\hline & $\mathrm{Fe}$ & $\mathrm{Al}$ & $\mathrm{Si}$ & $\mathrm{Mg}$ & $\begin{array}{c}\sum \mathrm{Fe}, \mathrm{Al}, \\
\mathrm{Si}, \mathrm{Mg}\end{array}$ & $\mathrm{Ca}$ & & & \\
\hline 1 & 0.004 & $<0.002$ & 0.001 & 0.01 & 0.0152 & - & 0.122 & 217 & 44 \\
\hline 2 & 0.005 & 0.039 & 0.004 & 0.033 & 0.076 & - & 0.44 & 83 & 44.5 \\
\hline 3 & 0.07 & 0.025 & $<0.001$ & $<0.01$ & 0.095 & - & 0.35 & 79 & 34 \\
\hline 4 & 0.06 & 0.012 & 0.001 & 0.024 & 0.097 & - & 0.35 & 88 & 34 \\
\hline 5 & 0.04 & 0.028 & $<0.001$ & $<0.01$ & 0.032 & 0.03 & 0.35 & 85 & 36 \\
\hline 6 & 0.04 & 0.035 & $<0.001$ & 0.030 & 0.105 & 0.04 & 0.47 & 71 & 42 \\
\hline 7 & 0.06 & 0.031 & 0.001 & $<0.01$ & 0.092 & 0.033 & 0.29 & 70 & 27 \\
\hline 8 & 0.07 & 0.04 & $<0.001$ & 0.022 & 0.132 & 0.024 & 0.182 & 69 & 30 \\
\hline 9 & 0.038 & 0.022 & $<0.001$ & 0.016 & 0.076 & 0.02 & 0.222 & 97 & 43 \\
\hline
\end{tabular}

* all elements with symbol $<$ are below the detection limit of AAS (method used to determine the content) ** alloys in each sample contained $0.001 \% \mathrm{Ag}$, and cumulative $0.005 \%$ of $\mathrm{Cu}, \mathrm{Ni}, \mathrm{Pb}, \mathrm{Sb}$ and $\mathrm{Zn}$

Table 4: The values of the creep rate, rupture time and relative elongation depending on the content of impurities at a temperature of 1400 ${ }^{\circ} \mathrm{C}$, at a stress of $5 \mathrm{MPa}$, for the alloy PtRh5Pd15

\begin{tabular}{|c|c|c|c|c|c|c|c|c|c|}
\hline \multirow[b]{2}{*}{ Sample } & \multicolumn{6}{|c|}{ Content of impurities / \% (wt.) } & \multirow[b]{2}{*}{$\dot{\varepsilon} / \% \mathrm{~h}^{-1}$} & \multirow[b]{2}{*}{$t / h$} & \multirow[b]{2}{*}{$\mathrm{A} / \%$} \\
\hline & $\mathrm{Fe}$ & $\mathrm{Al}$ & $\mathrm{Si}$ & $\mathrm{Mg}$ & $\begin{array}{c}\sum \mathrm{Fe}, \mathrm{Al}, \\
\mathrm{Si}, \mathrm{Mg}\end{array}$ & $\mathrm{Ca}$ & & & \\
\hline 1 & $<0.004$ & 0.009 & 0.018 & $<0.01$ & 0.026 & 0.011 & 1.3 & 20 & 32 \\
\hline 2 & $<0.004$ & 0.014 & 0.001 & 0.022 & 0.036 & 0.011 & 1.3 & 17 & 29 \\
\hline 3 & 0.004 & 0.009 & 0.002 & $<0.01$ & 0.051 & $<0.01$ & 2.4 & 13 & 39 \\
\hline
\end{tabular}

$*$ all elements with symbol $<$ are below the detection limit of AAS (method used to determine the content)

** All samples contain $<0.005 \% \Sigma$ : Cu, Ni and Zn; Samples No. 1 and No. 2 contain $0.001 \%$ Ag; Sample No. 3 contains $0.01 \%$ Ag

Table 5: The values of the creep rate, rupture time and relative elongation depending on the content of impurities at a temperature of 1400 ${ }^{\circ} \mathrm{C}$, at a stress of $5 \mathrm{MPa}$, for the alloy PtRh10Pd25Ru1.5

\begin{tabular}{|c|c|c|c|c|c|c|c|}
\hline \multirow{2}{*}{ Sample } & \multicolumn{4}{|c|}{ Content of impurities / \% (wt.) } & \multirow{2}{*}{$\dot{\varepsilon} / \% \mathrm{~h}^{-1}$} & \multirow{2}{*}{$\mathrm{t} / \mathrm{h}$} & \multirow{2}{*}{$\mathrm{A} / \%$} \\
\hline & $\mathrm{Fe}$ & $\mathrm{Cu}$ & $\mathrm{Al}$ & $\mathrm{Si}$ & & & \\
\hline 1 & 0.01 & 0.004 & $<0.002$ & $<0.001$ & 0.39 & 53 & 31 \\
\hline 2 & 0.065 & 0.003 & $<0.002$ & 0.019 & 0.43 & 28.5 & 11.5 \\
\hline 3 & 0.013 & 0.006 & 0.018 & 0.019 & 0.35 & 24 & 10 \\
\hline 4 & 0.053 & 0.004 & $<0.002$ & $<0.001$ & 0.48 & 29 & 16 \\
\hline 5 & 0.04 & 0.003 & 0.018 & 0.01 & 0.46 & 29 & 12.5 \\
\hline
\end{tabular}

* all elements with symbol $<$ are below the detection limit of AAS (method used to determine the content)

** investigated alloy also contains $<0.003 \% \mathrm{Mg}$; and $<0.005 \%$ of $\mathrm{Zn}, \mathrm{Ni}$ and $\mathrm{Pb}$ 
conditions. At the minimum content of non-precious impurities (Fe, Al, Si and $\mathrm{Mg}$ ) of $0.015 \%$ (sample No. 1), properties that characterize the resistance at high temperatures are 1.53.0 times higher than in sample No. 8 with the maximum content of the afore mentioned impurities of $0.132 \%$. Also, from Table 3, it can be seen that the rupture time significantly decreases with increasing content of impurities, while the relative elongation slightly decreases with the increase of the total content of impurities. Similar rules were also observed for alloys PtRh5Pd15 and PtRh10Pd25Ru1.5.

The characteristics of high temperature resistance of PtRh20Pd10Ir0.1Au0.1 alloy, at a temperature of $1400^{\circ} \mathrm{C}$ and a stress of $5 \mathrm{MPa}$, are presented in Table 6 .

Based on the results in Table 6 it can be concluded that for the tested alloy with the increase in the total content of ten most abundant impurities (Al, Fe, $\mathrm{Si}, \mathrm{Mg}, \mathrm{Pb}, \mathrm{Sb}, \mathrm{Zn}$, $\mathrm{Sn}, \mathrm{Cu}, \mathrm{Ni}$ ) from $0.01 \%$ to $0.083 \%$ wt., at a temperature of $1400{ }^{\circ} \mathrm{C}$ and a stress of $5 \mathrm{MPa}$, rupture time decreases five times, relative elongation four times and creep rate increases twice, which shows excellent agreement of the results with literature data ${ }^{19,21,22}$.

Based on the results presented above it can be concluded that increasing the sum of specified impurities results in a negative impact on the lifetime and plasticity of alloy PtRh20Pd10Ir0.1Au0.1, at high temperatures. Increasing the total content of impurities in the examined alloy from 0.015 to $0.083 \%$ (wt.) was followed by the accumulation of impurity atoms in the grain and subgrain boundaries, as shown in Figure 1.

It is obvious that the accumulation of impurity atoms at the grain boundaries leads to an increase in the total volume of the borders, which results in the creation of a very brittle structure that cracks relatively quickly in the processing as well as in the exploatation process at high temperatures. Namely, at the concentration of impurities of $0.01 \%$ and lower, the changes in structure are not observed and alloy possesses high plasticity and temperature resistance. Increasing the concentration of any impurity, to the hundredths or thousandths of percent, in platinum alloys, does not cause changes in composition of grain boundaries which would be observed under an optical microscope, but could be substantially responsible for the decrease of the relative elongation and the destruction time at $1400{ }^{\circ} \mathrm{C}$.

The structure of alloy PtRh20Pd10Ir0.1Au0.1 without the presence of impurities is presented in Figure 2. The grain size before testing was $0.057 \mathrm{~mm}$, and after the high temperature creep test it was $0.0267 \mathrm{~mm}$.
Microstructure of PtRh20Pd10Ir0.1Au0.1 alloy sample, containing impurities above $0.0286 \%$ (wt.), is shown in Figure 3. It is characterized by high porosity and difference in grain size before (average grain diameter is $0.034 \mathrm{~mm}$ ) and after the high temperature creep (grain size is $0.174 \mathrm{~mm}$ ).

Based on these results, it can be concluded that after plastic deformation by creep testing, average grain diameter of alloy, with impurities in an amount of $0.0286 \%$, is significantly bigger compared to the average grain diameter of the alloy without impurities. Impurities accumulated in the grain boundaries have resulted in a large porosity and accelerated intercrystalline destruction.

Intercrystalline fracture (Figure 4) occurs at grain boundaries and is characteristic when the material is exposed to low stress, low deformation speed and high temperatures.

Increased sensitivity of platinum alloys at high temperatures, containing a large number of impurities indicates to particular importance of the purity of the initial metals used for production of alloy.

Table 7 shows the influence of the control impurities present in refined platinum, rhodium and palladium on a high-temperature resistance of alloy PtRh20Pd10Ir0.1Au0.1 at $1400{ }^{\circ} \mathrm{C}$, at a stress of $5 \mathrm{MPa}$.

It is obvious that, when comparing the same or similar concentrations of $\mathrm{Pb}, \mathrm{Ag}$, and $\mathrm{Mg}$, rupture time of the obtained samples is higher at lower Si content. The content of $\mathrm{Fe}, \mathrm{Cu}$, Ni and Ti within the specified concentration does not show a significant effect on the characteristics of high temperature resistance and plasticity of samples made from different charges.

Constant and controlled composition of impurities in the starting charges is the main condition for obtaining platinum alloys with stable structures and characteristics. For that purpose, for the synthesis of alloys one should always strive to use platinum metals with high purity, which is achieved by multistage refining of them, so the final products would be of satisfying composition and quality.

On the mutual effect of impurities with platinum group metals, as well as their interaction, it is best to judge on the basis of the phase diagrams ${ }^{19-21}$. When considering the binary and multicomponent phase diagrams only interaction of 2-6 primary and alloying elements with a maximum of ten impurities should be taken into account.

Impurities such as $\mathrm{Fe}, \mathrm{Cu}, \mathrm{Ni}$, form solid solutions with platinum group metals, having a melting point lower than the melting point of the main and alloying elements. From such solid solutions, with a decrease in temperature, different

Table 6: The characteristics of high temperature resistance of alloy PtRh20Pd10Ir0.1Au0.1 depending on the total content of impurities

\begin{tabular}{|c|c|c|c|c|c|c|c|c|c|c|c|c|c|c|c|}
\hline \multirow{2}{*}{ Sample } & \multicolumn{12}{|c|}{ Content of impurities / $10^{-3} \%$ (wt.) } & \multirow{2}{*}{$\dot{\varepsilon} / \% \mathrm{~h}^{-1}$} & \multirow{2}{*}{$t / h$} & \multirow{2}{*}{$A / \%$} \\
\hline & $\mathrm{Ag}$ & $\mathrm{Fe}$ & $\mathrm{Mg}$ & $\mathrm{Al}$ & $\mathrm{Si}$ & $\mathrm{Pb}$ & $\mathrm{Sb}$ & $\mathrm{Sn}$ & $\mathrm{Zn}$ & $\mathrm{Cu}$ & $\mathrm{Ni}$ & $\Sigma$ & & & \\
\hline 1 & 0.5 & 2.6 & 0.03 & 5 & 0.02 & 5 & 0.03 & 0.07 & 0.8 & 0.8 & 0.7 & 15.55 & 0.07 & 340 & 48 \\
\hline 2 & 19 & 6 & 3 & 3 & 4 & 8 & 8 & 10 & 10 & 8 & 4 & 83 & 0.14 & 76 & 12 \\
\hline
\end{tabular}




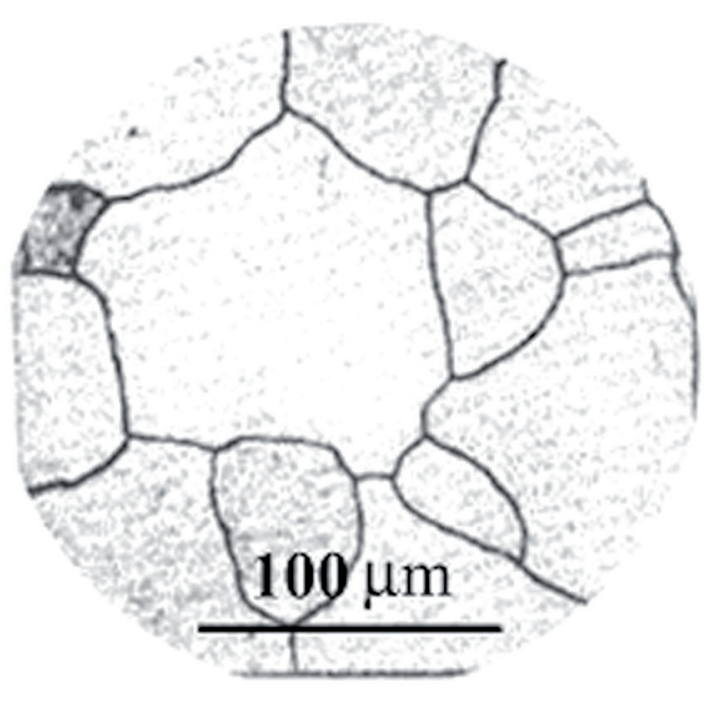

a)

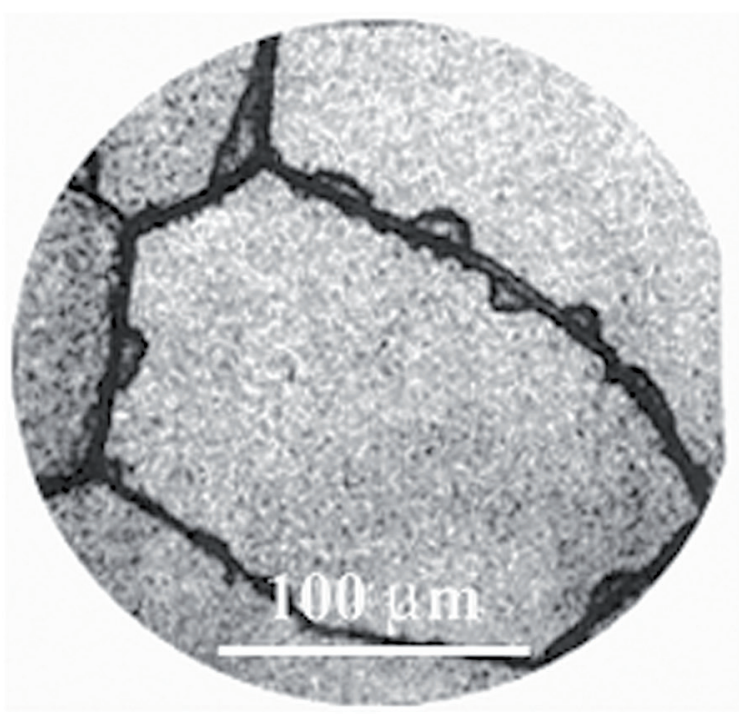

b)

Figure 1: The microstructure of the sample PtRh20Pd10Ir0.1Au0.1 with total content of the impurities a) $0.015 \%$ (wt.), $70 \mathrm{x}$; b) $0.083 \%$ (wt.), (magnification 200x)

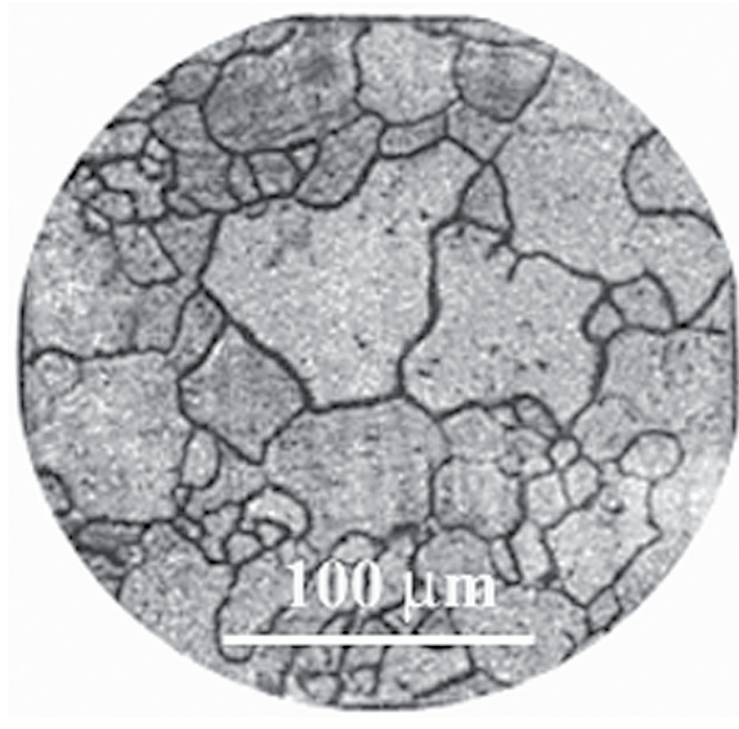

a)

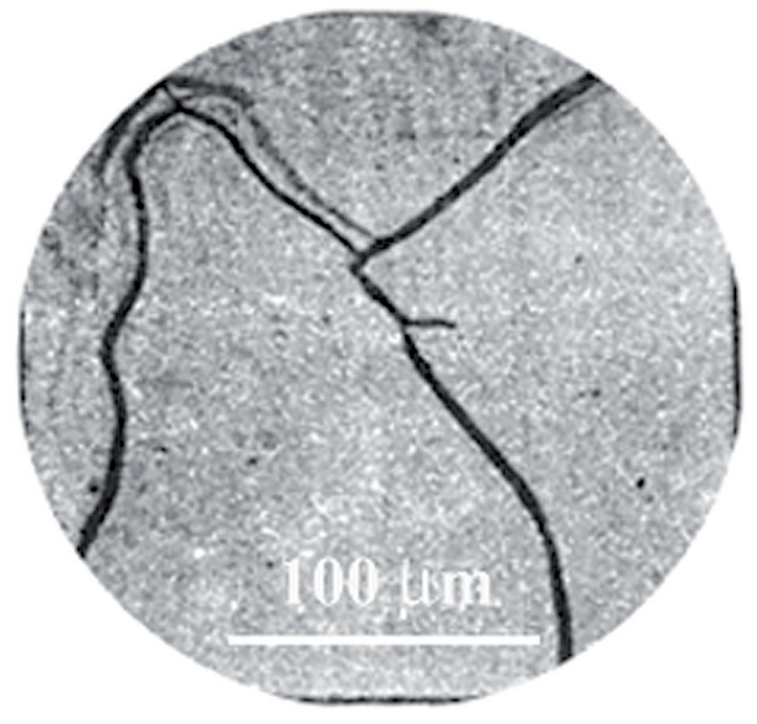

b)

Figure 2: Microstructure of sample composition PtRh20Pd10Ir0.1 Au0.1 without impurities: a) before and b) after creep, at $1400{ }^{\circ} \mathrm{C}$ and a stress of $5 \mathrm{MPa}$, close to the rupture point (magnification 200x)

transformations occur with formation of chemical compounds, damaging in the further exploitation of such materials ${ }^{22}$.

Impurities such as $\mathrm{Si}, \mathrm{Ag}, \mathrm{Pb}, \mathrm{Sn}, \mathrm{Sb}, \mathrm{Bi}, \mathrm{P}, \mathrm{S}, \mathrm{Se}, \mathrm{Te}, \mathrm{As}$, $\mathrm{Mg}, \mathrm{Zn}, \mathrm{Ba}, \mathrm{Al}$, with platinum group metals form sparingly soluble and brittle compounds ${ }^{22}$. The resulting compounds (such as Pt and Pd silicides), lead to relatively rapid fracture and destruction of materials at high temperature operation.
The probability of interaction of impurities with the platinum group metals is even greater and more significant if the concentration of the impurities is higher in those metals.

Technological and exploitation properties of platinum metals and alloys can be significantly altered in the presence of very small amounts of impurities (within hundredths and thousandths of a percent). In the presence of very small 


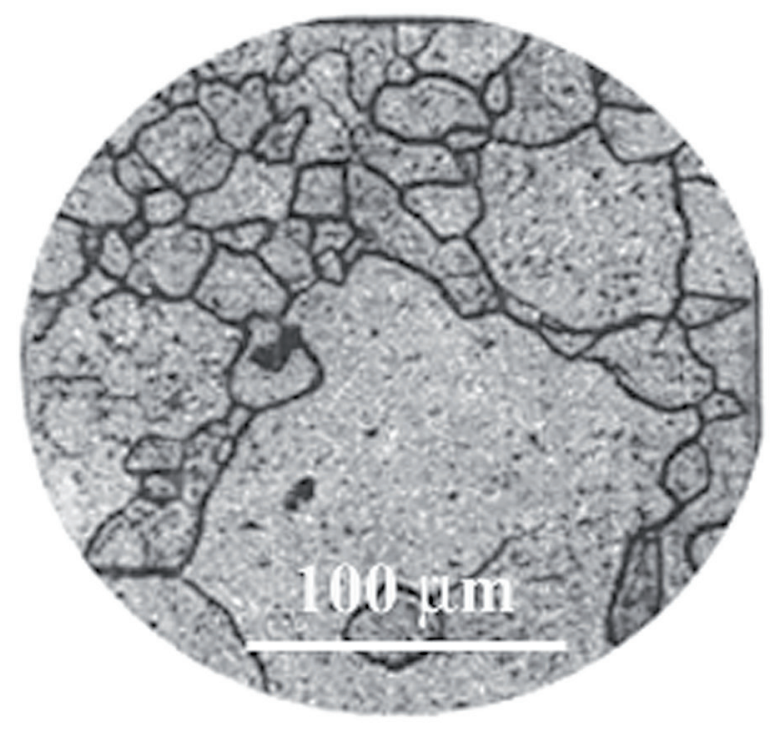

a)

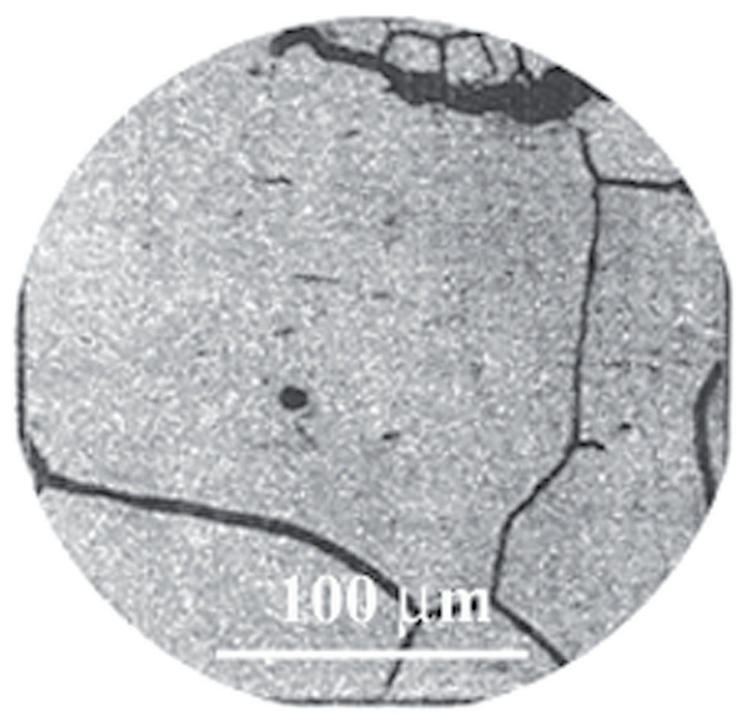

b)

Figure 3: Microstructure of sample composition PtRh20Pd10Ir0.1Au0.1 with impurities content of $0.0286 \%$ : a) before and b) after creep, at $1400{ }^{\circ} \mathrm{C}$ and a stress of $5 \mathrm{MPa}$, close to the rupture point (magnification $200 \mathrm{x}$ )

contents of impurities in the volume of metals or alloys, their concentration in certain zones (intercrystalline zone or zone within the crystal-grain itself) can be very high.

The equilibrium segregation of impurities takes, by rule, an area of one to ten nanometers, although in most cases an enrichment in impurities is limited by monolayer segregation of atoms equal to or slightly greater than the intercrystal zone with width of the 2-3 atomic layers.

The equilibrium segregation occurs as a result of diffusion of impurities to the grain boundaries while creating a concentration gradient. It is most common for phase diagrams with low solubility of impurities in the crystal lattice metalbase, as well as for the large differences in atomic diameters of impurities and the base metal.

For the studied phase diagrams of platinum with $\mathrm{Fe}$, $\mathrm{Ni}$, and $\mathrm{Cu}$ grain boundaries are even more enriched with impurities if their solubility limit is lower. With the reduction of impurities solubility limit up to the $1 \times 10^{-3} \%$ (at.), their concentration in the intercrystal zone of the metal-base may reach $10 \%$ (at.), ie. may be 10.000 times larger than in alloy volume.

Based on the afore mentioned, we reach the conclusion that practically insoluble or slightly soluble impurities such as $\mathrm{Ba}, \mathrm{P}, \mathrm{As}, \mathrm{Si}, \mathrm{Bi}$ and $\mathrm{Pb}$ show a high tendency towards forming equilibrium segregations, compared to the $\mathrm{Fe}, \mathrm{Ni}$, $\mathrm{Cu}, \mathrm{Ag}, \mathrm{Mg}, \mathrm{Zn}, \mathrm{Al}$ and $\mathrm{Sb}$ which with platinum form a continuous series or wide area (on platinum side) of solid solutions.

The equilibrium segregation of impurities leads to a reduction in deformation energy of the crystal lattice in the area of their existence, while reducing the Gibbs energy of intergrain borders.

Impurities accumulated at the grain boundaries may react with each other and lead to strengthening or weakening of segregations of that element or some other element.

In the first case, at the same sign of the atomic range of deviation between two impurities compared to metalbase, the intercrystalline zone will be more enriched with atoms of impurity which has a greater range of deviation in absolute values. In the second case, at the different sign of the atomic deviation and equal atomic concentrations of the two impurities, it comes to the formation of complex of atoms of those impurities and the equilibrium segregation weakens.

Segregation gets stronger in the case when the impurities absorbed on the surface of the crystal have the same sign and close values of deviation range, at the same time.

In this way, it can be expected that in cases when the removal of hamful impurities from the alloy is very difficult, their impact can be also minimized with the introduction of less harmful impurity or impurity with opposite sign of deviation range.

Based on the atomic diameter of platinum which is 0.139 $\mathrm{nm}$, it is possible to form a series of ranges of deviation of impurities atomic diameters.

Size of the range of deviation $(\Delta r)$ of atomic diameters of platinum and impurities, in the case when the diameter of platinum is larger $(\Delta \mathrm{r}+)$ or smaller $(-\Delta \mathrm{r})$ than diameters of impurities is given in Table 8 .

Based on the values shown in Table 8 it can be concluded that $\mathrm{Zr}$ reduces the equilibrium segregation and negative 

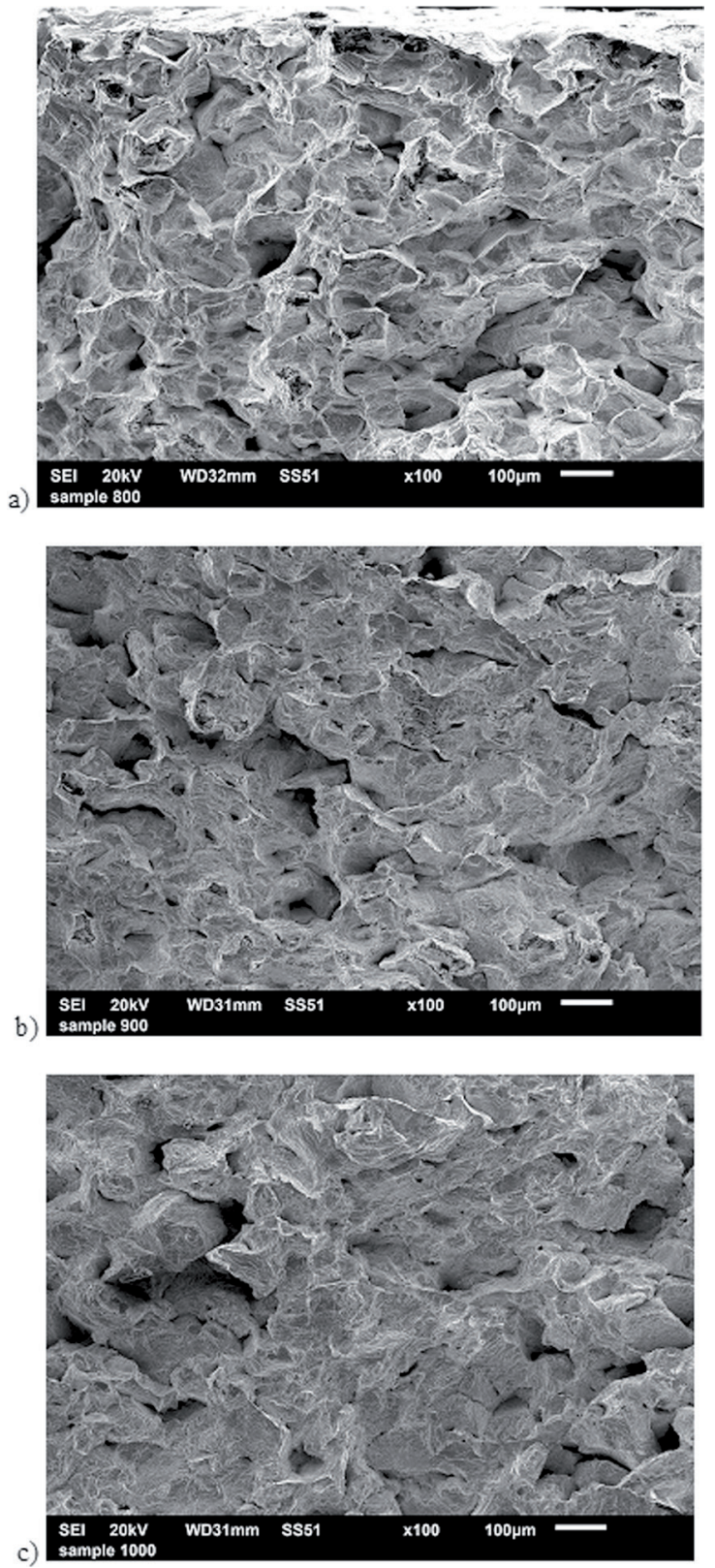

Figure 4: Examples of intercrystalline fracture at a) 800 , b) 900 and c) $1000^{\circ} \mathrm{C}$ for PtRh20Pd10Ir0.1Au0.1 alloy

impact of impurities, such as $\mathrm{Si}$ and $\mathrm{P}$ in the investigated platinum alloys. Bismuth can somewhat neutralize the negative impact and accumulation of impurities such as $\mathrm{Fe}$, $\mathrm{Cu}, \mathrm{Cr}, \mathrm{Co}$, As and $\mathrm{Ni}$.

The most severe form is the presence of impurities with approximate values of the divergency range, and of the same sign, such as $\mathrm{Al}$ and $\mathrm{Ag}$ as a pair, and $\mathrm{Zn}$ and $\mathrm{Si}$ as a second pair. In these cases probability of equilibrium segregation of each pair of impurities increases, as well as their negative impact on the technological and exploitation properties of platinum alloys.
However, in practical terms it is difficult to predict and even harder to manage the equilibrium segregation process of impurities in platinum alloys.

In real conditions in the formation of equilibrium segregation dozen of impurities can participate and that process can be very dependent on their mutual effect, interactions with the metal-base and alloying elements with simultaneous dependence of the temperature-time factor.

\section{Conclusion}

In this paper are presented results of the influence of individual impurities, as well as groups of impurities on resistance to plastic deformation and fracture at elevated temperatures, for the following alloys: PRh7, PtRh10, PtRh5Pd15, PtRh10Pd25Ru1.5 and PtRh20Pd10Ir0.1Au0.1.

Generally, in all investigated alloys, at elevated temperatures, with increasing of total content of impurities ( $\mathrm{Fe}, \mathrm{Si}, \mathrm{Al}$ and $\mathrm{Mg}$ ) from 0.013 to $0.068 \%$ (wt.) it was observed an increase in creep rate, alongside reduction of relative elongation and time to fracture.

The increase in total impurity content (from $0.015-0.083 \%$ (wt.)) in investigated alloys is accompanied by accumulation of their atoms at grain boundaries, resulting in occurrence of brittle and fragile structure.

At the same or similar contents of $\mathrm{Pb}, \mathrm{Ag}$ and $\mathrm{Mg}$, time to fracture is longer, at lower $\mathrm{Si}$ contents. The content of $\mathrm{Fe}$, $\mathrm{Cu}, \mathrm{Ni}$ and Ti within the limits of observed contents does not show significant negative impact on the high temperature properties of the alloy.

For the alloys PtRh10, PtRh5Pd15 and PtRh10Pd25Ru1.5 the rupture time significantly decreases with increasing content of impurities, while the relative elongation slightly decreases with the increase of the total content of impurities.

For PtRh20Pd10Ir0.1 Au0.1 alloy resuts of investigation are showing that with increase in total content of ten most abundant impurities (Al, Fe, $\mathrm{Si}, \mathrm{Mg}, \mathrm{Pb}, \mathrm{Sb}, \mathrm{Zn}, \mathrm{Sn}, \mathrm{Cu}$, $\mathrm{Ni}$ ) from $0.01 \%$ to $0.083 \%$ wt., rupture time decreases five times, relative elongation four times and creep rate increases twice, which is in agreement with literature data.

Based on these results, it can be concluded that after plastic deformation by creep testing, average grain diameter of alloy, with impurities in an amount of $0.0286 \%$, is significantly bigger compared to the average grain diameter of the alloy without impurities. Impurities accumulated in the grain boundaries have resulted in a large porosity and accelerated intercrystalline destruction.

The probability of interaction of impurities with the platinum group metals is even greater and more significant if the concentration of the impurities is higher in those metals.

Technological and exploitation properties of platinum metals and alloys can be significantly altered even in the 
Table 7: The influence of control impurities content in the alloy PtRh20Pd10Ir0.1Au0.1 on high temperature properties

\begin{tabular}{|c|c|c|c|c|c|c|c|c|c|c|c|c|}
\hline \multirow{2}{*}{ Sample } & \multicolumn{9}{|c|}{ Content of the impurities $/ 10^{-3} \%$ (wt.) } & \multirow{2}{*}{$\dot{\varepsilon} / \% \mathrm{~h}^{-1}$} & \multirow{2}{*}{$t / h$} & \multirow{2}{*}{$A / \%$} \\
\hline & $\mathrm{Si}$ & $\mathrm{Fe}$ & $\mathrm{Pb}$ & $\mathrm{Ag}$ & $\mathrm{Ti}$ & $\mathrm{Cu}$ & $\mathrm{Ni}$ & $\mathrm{Mg}$ & $\Sigma$ & & & \\
\hline 1 & 1.8 & 0.3 & 0.6 & 0.7 & - & 0.2 & - & 0.8 & 4.4 & 0.09 & 175 & 23 \\
\hline 2 & 1.6 & 0.1 & 0.8 & 0.9 & 0.2 & - & 0.6 & 0.8 & 5. & 0.24 & 216 & 65 \\
\hline 3 & 0.4 & 1.7 & 0.6 & 0.7 & - & 0.2 & - & 0.8 & 4.4 & 0.12 & 276 & 50 \\
\hline 4 & 0.2 & 1.5 & 0.8 & 0.9 & 0.2 & - & 0.6 & 0.8 & 5 & 0.05 & 430 & 70 \\
\hline
\end{tabular}

Table 8: Values of the range of deviation $(\Delta \mathrm{r})$ for impurities

\begin{tabular}{lccc}
\hline Element & $\Delta \mathrm{r} / \mathrm{nm}$ & Element & $\Delta \mathrm{r} / \mathrm{nm}$ \\
\hline $\mathrm{Zn}$ & +0.006 & $\mathrm{As}$ & -0.009 \\
$\mathrm{Si}$ & +0.021 & $\mathrm{Sn}$ & -0.012 \\
$\mathrm{P}$ & +0.021 & $\mathrm{Mg}$ & -0.021 \\
$\mathrm{Cu}$ & +0.011 & $\mathrm{Zr}$ & -0.021 \\
$\mathrm{Fe}$ & $\mathrm{Sb}$ & -0.012 \\
$\mathrm{Cr}$ & +0.015 & $\mathrm{~Pb}$ & -0.036 \\
$\mathrm{Co}$ & +0.014 & $\mathrm{Y}$ & -0.039 \\
$\mathrm{Ni}$ & +0.014 & $\mathrm{Bi}$ & -0.016 \\
$\mathrm{Al}$ & +0.014 & $\mathrm{Ca}$ & -0.058 \\
$\mathrm{Ag}$ & -0.004 & $\mathrm{Ba}$ & -0.078 \\
$\mathrm{Ti}$ & -0.005 & $\mathrm{~K}$ & -0.088 \\
\hline
\end{tabular}

presence of very small amounts of impurities because their concentration in certain zones (intercrystalline zone or zone within the crystal-grain itself) can be very high. Based on the afore mentioned, we reach the conclusion that practically insoluble or slightly soluble impurities such as $\mathrm{Ba}, \mathrm{P}, \mathrm{As}, \mathrm{Si}, \mathrm{Bi}$ and $\mathrm{Pb}$ show a high tendency towards forming equilibrium segregations, compared to the $\mathrm{Fe}, \mathrm{Ni}, \mathrm{Cu}, \mathrm{Ag}, \mathrm{Mg}, \mathrm{Zn}, \mathrm{Al}$ and $\mathrm{Sb}$ which with platinum form a continuous series or wide area (on platinum side) of solid solutions.

Impurities accumulated at the grain boundaries may react with each other and lead to strengthening or weakening of segregations of that element or some other element.

Alloys of Pt-Rh, Pt-Pd-Rh, Pt-Rh-Pd-Ru and Pt-RhPd-Ir-Au systems are primarily used in high temperature conditions, and accordingly, presented results contribute to a better understanding of their behavior in such working conditions.

\section{Acknowledgement}

The research results presented in this paper are the result of technological development project TR 34029 "Development of production technology of Pd catalystcatchers to reduce losses of platinum in high temperature catalysis processes", funded by the Ministry of Education, Science and Technological Development.

\section{References}

1. Gavin H. Platinum group metals research from a global perspective. Platinum Metals Review. 2010;54(3):166-171.

2. Preston E. Platinum in the glass industry. Platinum Metals Review. 1960;4(2):48-55.

3. Couderc C. Platinum Group Metals in Glass Making. Platinum Metals Review. 2010;54(3):186-191.

4. Ning Y, Yang Z, Zhao H. Platinum Recovery by Palladium Alloy Catchment Gauzes in nitric Acid Plants. Platinum Metals Review. 1996;40(2):80-87.

5. Yuantao N, Zhengfen Y. Platinum Loss from Alloy Catalyst Gauzes in Nitric Acid Plants. Platinum Metals Review. 1999;43(2):62-69.

6. Trumić B, Stanković D, Trujić V. Examining the surfaces in used platinum catalysts. Journal of Mining and Metallurgy $B$. 2009;45(1):79-87.

7. Wu B, Liu G. Platinum: Platinum-Rhodium Thermocouple Wire. Platinum Metals Review. 1997;41(2):81-85.

8. Funabiki M, Yamada T, Kayano K. Auto exhaust catalysts. Catalysis Today. 1991;10(1):33-43.

9. Biggs T, Taylor SS, van der Lingen E. The Hardening of Platinum Alloys for Potential Jewellery Application. Platinum Metals Review. 2005;49(1):2-15.

10. Wright JC. Jewellery-Related Properties of Platinum Low Thermal Diffusivity Permits Use of Laser Welding for Jewellery Manufacture. Platinum Metals Review. 2002;46(2):66-72.

11. Biggs T, Cortie MB, Witcomb MJ, Cornish LA. Platinum Alloys for Shape Memory Applications. Platinum Metals Review. 2003;47(4):142-156.

12. Biggs T, Witcomb MJ, Cornish LA. Martensite-type transformations in platinum alloys. Materials Science and Engineering: A. 1999;273-275:204-207.

13. Xiao F, Zhao F, Mei D, Mo Z, Zeng B. Nonenzymatic glucose sensor based on ultrasonic-electrodeposition of bimetallic $\operatorname{PtM}(\mathrm{M}=\mathrm{Ru}, \mathrm{Pd}$ and $\mathrm{Au})$ nanoparticles on carbon nanotubesionic liquid composite film. Biosensors and Bioelectronics. 2009;24(12):3481-3486.

14. Jacob KT, Priya S, Waseda Y. Thermodynamic properties and phase equilibria for Pt-Rh alloys. Metallurgical and Materials Transactions A. 1998;29(6):1545-1550.

15. Dereli G, Cagin T, Uludogan M, Tomak M. Thermal and mechanical properties of Pt-Rh alloys. Philosophical Magazine Letters. 1997;75(4):209-218. 
16. Battaini P. Microstructure Analysis of Selected Platinum Alloys. Platinum Metals Review. 2011;55(2):74-83.

17. Luyten J, de Keyzer J, Wollants P, Creemers C. Construction of modified embedded atom method potentials for the study of the bulk phase behaviour in binary Pt-Rh, Pt-Pd, Pd-Rh and ternary Pt-Pd-Rh alloys. Calphad. 2009;33(2):370-376.

18. Trumić B, Gomidželović L, Marjanović S, Krstić V, Ivanović A, Dimitrijević S. Pt-Rh Alloys: Investigation of Creep Rate and Rupture Time at High Temperatures. Materials Testing. 2013;55(1):38-42.
19. Ritvin EI, Medovoi LA. Vlianie fiziko-himicheskoj sledi na zharoprochnost merallicheskih materialov. Moskva: Nauka; 1974.

20. Savickij EM, Poljakova VP, Gorina NB, Roshan NR. Metalovedenie platinovih metalov. Moskva: Metalurgija; 1975.

21. Zaharov MV, Zaharov AM. Zharoprochnie splavi. Moskva: Metalurgija; 1983.

22. Ritvin EI. Zharoprochnost platinovih splavov. Moskva: Metalurgija; 1987. 